\title{
Adopting a role: A performance art in the practice of medicine
}

\author{
L Schweickerdt, BA Drama Hons \\ Skills Centre, School of Medicine, Sefako Makgatho Health Sciences University, Pretoria, South Africa
}

Corresponding author: L Schweickerdt (louise.schweickerdt@smu.ac.za)

\begin{abstract}
The practice of medicine has evolved a long way from its origin, where healing was practised as an art in ancient Greece. In current healthcare training, the focus is on clinical features and the treatment thereof. The connection to the arts in the practice of medicine has been lost - one of the reasons why students of medicine lose their empathy during their years of training. In this article, I explore the correlations between the art of performance and medicine, with particular focus on the training of students of medicine. The notion is investigated that if medical students learn to adopt a professional role by incorporating certain non-assuming facets of the art of performance into their training, they could learn to step in and out of the role of healthcare practitioner (HCP). This action could assist them not only in reflecting on their practice as HCPs, but could also afford them the opportunity of debriefing, as they are equipped with the tools to view their role as HCPs more objectively. The acquisition of tools to step in and out of the role of HCP, complemented by the process of debriefing through reflection, could afford students of medicine the ability to deal with the emotional labour that training to become a future HCP brings. In turn, this may empower them to retain the empathy that they inherently possessed when they enrolled as students.
\end{abstract}

Afr J Health Professions Educ 2018;10(1):3-4. DOI:10.7196/AJHPE.2018.v10i1.950

In ancient Greece, where western medicine originated, rituals of healing took place in the form of performances - with an observing audience. ${ }^{[1]}$ Greek physicians believed in the importance of the role of theatre in the treatment of illness. ${ }^{[2}$

The connection between the art of healing and the art of performance, which was formed in ancient Greece, still exists, ${ }^{[3-5]}$ as also becomes apparent when considering that an operating theatre and a performance theatre are both still referred to as 'theatres'. However, modern healthcare training focuses predominantly on clinical features and the treatment thereof, which is one of the reasons why students of medicine lose their empathy during their training. ${ }^{[4,5]}$

The acquisition of tools to step in and out of the role of a healthcare practitioner (HCP), could equip students of medicine with the ability to 'reflect on their own thoughts, feelings, inclinations, practice and experience. ${ }^{[6]}$ This could be regarded as a process of debriefing, as it will allow them to reconnect with their 'inner selves' outside the scope of their role as HCPs.

By drawing attention to aspects of the art of performance in relation to healthcare training, this article explores the notion that, if students of medicine are trained in a way that enables them to reconnect with the art of performance, they could learn to adopt a role that will equip them with the necessary tools to cope with the emotional labour that their training requires. ${ }^{[3,5]}$

\section{Adopting a role}

In The Presentation of Self in Everyday Life, Goffman ${ }^{[3]}$ investigates the concept of roles that human beings adopt, specifically when they need to adhere to a social structure confined to a building or a space.

Goffman refers to white coats as creating the impression that the manner in which tasks 'performed' by persons wearing such coats are standardised, clinical and confidential. ${ }^{[3]}$ Donning a white coat, adding a stethoscope and other features of medical care, could afford students of medicine the possibility of stepping into the role of a HCP while simultaneously stepping away from the self - just as an actor's costume and make-up assist in transforming them into the character to be portrayed.

Goffman ${ }^{[3]}$ also refers to a 'setting', which is a space that includes 'furniture, décor, physical layout and other background items which supply the scenery and stage props for the spate of human action played out before, within or upon it. This setting might refer to a set on stage that allows the actor to believe in the world of the drama that is about to unfold, as his visual perception contributes to the belief in his surroundings. Medical students might learn to adapt to the setting in a hospital or consultation room in a similar manner: a setting reminding them that they are surrounded by an environment that offers certain prerequisites for them to take on the role of a HCP.

Sinclair ${ }^{[4]}$ a medical doctor and anthropologist who returned to medical school to observe how students are trained, draws detailed similarities between the art of performance and that of medicine.

According to him, a strong connection between healthcare and the art of performance is suggested in the theatrical setting of ward rounds. Students learn to present their patients before the ears and eyes of an audience. ${ }^{[4]}$ Apart from the performance aspect that Sinclair ${ }^{[4]}$ refers to, the acquisition of medical terminology corresponds to the actor's internalisation of a stage script. Neither the medical student nor the actor uses their own words. Their inner selves can hide behind medical terminology or script.

The revolutionary director of the Russian stage, Constantin Stanislavski, ${ }^{[7]}$ dealt at length with the notion of the 'magic if'. The actor must remain authentic by acting 'as if' he found himself in the situation that the character is in.

Stanislavski's 'system' - or representational acting - stands in strong contrast to the Strasberg ${ }^{[8]}$ 'method acting'. In Strasberg's method, the actor immerses his entire being into the character he is portraying. The line between the character and the actor's psyche becomes inextricably intertwined until it eventually dissolves and the actor is left in a state of confusion, with little or no connection to their own personal feelings. A comparison may be drawn between 'method' actors and students of 
medicine who lose touch with their inner selves in an attempt to immerse themselves into their medical identities as HCPs.

A strong correlation can also be drawn between Stanislavski's system and Strasberg's method and the role that students of medicine could adopt. Instead of immersing themselves into the world of their training, such as a method actor would do, students of medicine could be trained to adopt a role such as explained by Goffman ${ }^{[3]}$ or Stanislavski's 'magic if'. In turn, this could afford medical students the possibility of stripping the role when they leave work to return to an area that Goffman ${ }^{[3]}$ refers to as 'outside' and Sinclair ${ }^{[4]}$ refers to as the 'lay world'.

These are areas that bear no connection to any areas or settings where a professional role needs to be adopted. ${ }^{[3,4]}$ In theatrical terms, it could be the space that an actor returns to after having performed a role. These areas could offer the actor or students of medicine the possibility of rehabilitating the self through reflection as a means of debriefing. ${ }^{[6]}$ Here, students of medicine could internalise the experience, incorporating it as part of who they are when they do not need to adopt or portray the role of a HCP. Hence, this could assist them not to become overwhelmed by unresolved emotions so that the emotional labour required to be trained as a future HCP does not become too much to bear, with the loss of empathy as consequence. ${ }^{[4,5]}$

\section{Conclusion}

The practice of medicine has evolved from its origin, where healing was practised solely as an art in ancient Greece. Currently, healthcare training focuses predominantly on clinical features and the treatment thereof.

Students of medicine could benefit if they are given the tools to adopt a role as HCP instead of attempting to immerse themselves in the medical identity of a HCP. ${ }^{[3,4]}$ Incorporating some non-assuming facets of the art of performance into the training of medical students could assist them with the ability to step in and out of the role of HCP, which could afford them the opportunity to reflect on their actions to gain new insights into the strengths and weaknesses of their own practices. ${ }^{[6]}$ The process of reflection could be regarded as a strategy to debrief, which could provide them with the tools to deal with the emotional labour that the work demands. ${ }^{\left[{ }^{[5}\right]}$ This could enable them to retain the empathy they inherently possessed when they enrolled as students of medicine.

Acknowledgements. I am deeply indebted to Prof. Ina Treadwell, without whose insight and strong support none of this work would have been possible. I would also like to express immense gratitude towards Dr Champak Barua for believing in the concept and his selfless sharing of knowledge throughout the process.

Author contributions. Sole author.

Funding. None.

Conflicts of interest. None.

1. Clift S, Camic PM, eds. Oxford Textbook of Creative Arts, Health and Wellbeing. Oxford: Oxford University Press, 2016.

Christos FK, Sfakianakis C, Papathanasiou IV. Health care practices in ancient Greece: The Hippocratic ideal. J Med Ethics Hist Med 2016;7(6):1-6.

3. Goffman E. The Presentation of Self in Everyday Life. New York: Random House, 1959.

4. Sinclair S. Making Doctors: An Institutional Apprenticeship. Oxford: Berg Publishers, 1997.

5. Riley R, Weiss MC. A qualitative thematic review: Emotional labour in healthcare settings. J Adv Nurs 2015;72(1):6-17. https://doi.org/10.1111/jan.12738

6. Kirklin D. Humanities in medical training and education. Clin Med 2001;1(1):25-27. https://doi.org/10.7861 clinmedicine.1-1-25

7. Stanislavski C. An Actor Prepares. New York: Routledge, 1964

8. Strasberg L. A Dream of Passion: The Development of the Method. Boston: Little, Brown, 1987.

Accepted 16 August 2017 